\title{
CBR in the service of accident cases evaluating
}

\author{
Application to the safety of rail-road transport systems.
}

\author{
Lassaâd Mejri \\ RIADI-GDL Laboratory \\ Faculty of Science of Bizerte \\ University of Carthage \\ Tunisia
}

\author{
Sofian Madi, Henda Ben Ghézala \\ RIADI-GDL Laboratory, \\ National School of Computer Science \\ University of Manouba \\ Tunisia
}

\begin{abstract}
This paper introduces a research aiming at the development of a decision support system concerning the approval of automated railway transportation systems. The objective is to implement a valuation method for the degree of compliance of the automated transportation system in-group of safety standards by the analysis of the scenarios of accident. To reach this target, we envisaged an approach Rex (Return of experience) who draws the lessons of accidents / incidents lived and/or imagined by the experts of the analysis of security in the IFSTAAR. Our approach consists in offering a decision support in the side of the experts of the certification based on a reuse of the scenarios of accidents already validated historically on other approved transportation systems. This approach Rex is very useful since it provides to the experts a class of scenarios of accidents similar to the new case treated and getting closer to the context of new case. The Case-based reasoning is then exploited as a mode of reasoning by analogy allowing to choose and to recollect one under group of historical cases that can help in the resolution of the new case introduced by the experts. ProcessOriented Case-Based Reasoning (PO-CBR) is a growing application area in which $\mathrm{CBR}$ is used to address problems involving process data in a variety of specialized domains. POCBR systems often use structured cases. Our approach is characterized by a two-phased retrieval strategy. A first phase consists in retrieving a set of cases to be considered (a class of cases most similar to a problem to resolve). In a second phase, a more fine grained strategy is then applied to the pool of candidate cases already selected by the mean of similarity measures. This approach can enhance the process of retrieving cases compared to an exhaustive case-by-case comparison.
\end{abstract}

Keywords-componentSecurity of transport; Artificial Intelligence; Ontology; Case-Based Reasoning; Resolution scenario; Scenario of accident.

\section{INTRODUCTION}

A scenario of accident or of incident is seen as a dynamic evolution of a habitual situation in the transportation system until the point of attaining a risky situation. This undesirable situation in terms of security is then exploited to reinforce the security of the system by acting on functions of security and adequate automatisms. The experts of the certification have to study the transportation system in order to bring out its compliance with recognized guideline of railway security and have to decide to accord him an interim or final amenity before its bet in site.
In another side, the constructors of the transportation system put in contribution the report of security study given by the experts in order to improve the security level of their transportation systems. The simulation of accidents is an essential activity of the experts that puts in contribution the mind of analysis and of synthesis of the human experts. An analysis of the different components of the transportation system and their modes of faults allows envisaging the summed up faults of the system. These summed up faults when injected into the model of Petri allow to the experts to make scenarios of accidents. All scenarios made by the experts allow having an idea of the compliance degree of the transportation system offered by the constructor in norms and guidelines of security. Currently a model of feasibility of the approach based on case is under way. This model uses ontology of the domain of the transport allowing the unification of the vocabulary used in analysis of railway security.

\section{CONCEPT OF ACCIDENT SCENARIO}

A scenario of accident represents an unsecured situation concerning automated transport system. This potential insecurity should be solved by proposing a solution to be adopted in order to overcome the risk that it represents (example: collision between two underground oars or derailment of the way etc.). A scenario is a combination of circumstances that can lead to a danger. It is jointly described by attributes of situation that give an idea of insecurity and attributes of solution to adopt to ruin or to reduce the risk of insecurity. These descriptors take a census of several parameters, which report a risk / functions of security / actors / the geographical zone / breakdowns touching a part of the system / solutions adopted to ruin risk (See Figure 1.)

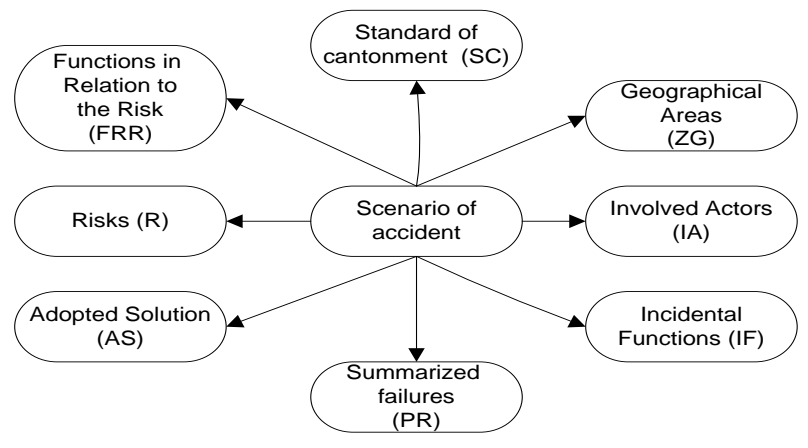

Figure 1. The parameters of static description of an accident scenario 


\section{PREVIOUS WORKS}

This problem of analyzing security was already treated according to a first approach during the thesis jobs of [17] and [10]. The accomplished jobs had led, first, to the implementation of a feasibility model and to the achievement of an acquisition and classification system of the scenarios of accidents called ACASYA. In order to help the experts in their activity of valuation of accidents scenarios, ACASYA articulates around three supplementary stages (See figure 2):

- First, classify the scenario of accident in a predefined class with the assistance of classification algorithm. Every class of scenarios is characterized by a description composed by the most pertinent scenarios descriptors of the class.

- Then, evaluate the scenario offered by the constructor in reference to the membership class found in the previous stage to restrain the exploration space. The evaluation consists of testing the completeness and the coherence of a scenario of accident.

- Generate new unsecured situations by putting in contribution the superfluous and/or missing elements of description discerned in valuation by EVALSCA.

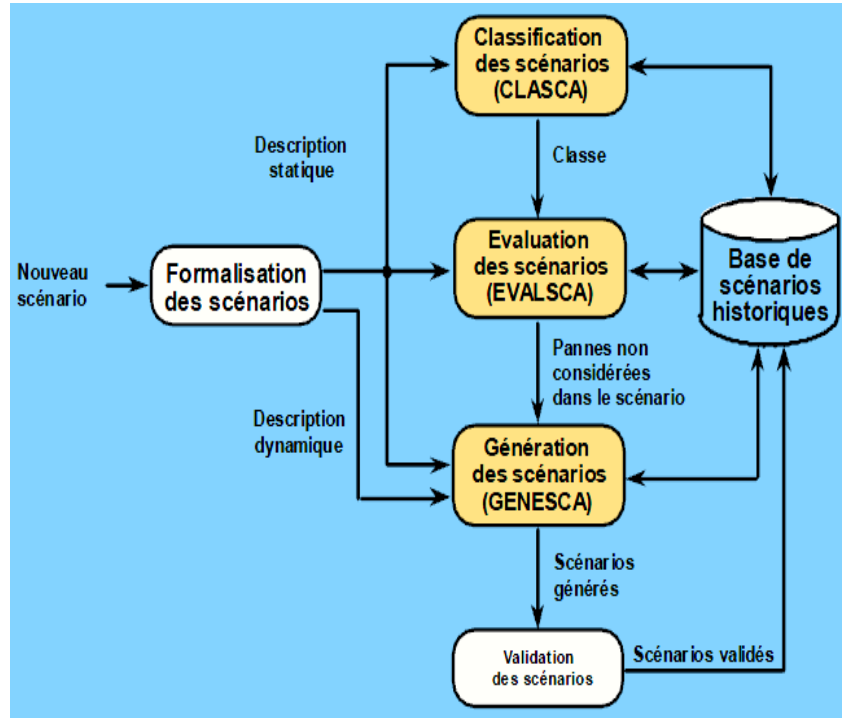

Figure 2. ACASYA System Architecture [17], [10].

The first results of the valuation of our research works applied to the domain of the analysis of security [17], allowed us to try so to identify a more generic model of acquisition of knowledge [20], and a stage step more general for the resolution of problem [19].

\section{OUR CURRENT RESEARCH FOCUS}

In the previous works, several borders were disclosed and deserve one particular attention for our current works:

- ACASYA limited itself to exploit the static description of the scenario of accident. Although, this description is related easily to an example of training (chip of pair $<$ Attribute/value>), it does not allow only to report the wealth of an accident which makes intercede several material/software and human actors and implicates several automatism and functions of security, etc. It would be then natural to take advantage from all the forms of description of scenario: dynamic, textual and graphic description.

- The static aspect of the scenarios of accidents represents the general context of the problem put down by accident as well as precautionary or corrective measures (adopted solutions). However, it gives no idea of the holding of scenarios in time and in space. It is only the dynamic description, which takes responsibility for it. This dynamic description takes a well part in simulation.

- The language of description used in the static panel of the scenarios of accidents misses a total coherence and do not consults any terminology or vocabulary well defined in the domain. It is then opportune to supplement this language in order to set up a domain ontology, which would raise all used concepts, relations between concepts and authorities of these concepts in the domain. This ontology would be a reference frame to describe the scenarios of accidents and to measure their completeness and pertinence of syntactic and semantic angle.

- ACASYA operates in classifying theoffered scenarios of accidents by the constructor to report its acceptability to a group of classes of scenario predefinedby the experts. ACASYA leads by training for each from the predefined classes to a characteristic description of the class under the form <Attribute/Values/frequency of appearance in its class $>$. One brings closer then according to a similarity measure to the description of a class of scenarios to a new scenario (static description): the one for whom it represents the best similarity score according to the common attributes/values. It would be more opportune to go through the different scenarios of the class in order to measure similarity inter-scenarios. This, to spot the best historical scenarios of accident (the most similar to the new scenario) stocked in the database. This include a case-based reasoning (CBR) and not a purely inductive mechanism. Indeed, we consider CBR to be the means of the return of experience (Rex) in the field of the analysis of security.

- Another problem in the existing system is because of knowledge representation model (scenario) and the problem resolution model (induction): these are two separated elements and remind a classic approach of treatment. Moreover, in an approach based on knowledge, it turns more and more in research to include the method of resolution of problem.

The following sections are then going to be dedicated to introduce the model of case as we envisage it as well as at jobs undertaken in the group to set up the ontology of domain. This model of case is envisaged to be honest with dynamic description and favors the simulation of case of accidents to report notably the analysis of security. The final section will be 
reserved for the presentation of the general steps based on case adopted for the strengthening of the analysis of security and to help in the decision of the experts.

\section{CASE-BASED REASONING (CBR)}

The Case Based Reasoning is a type of reasoning in Artificial Intelligence AI. Case based reasoning means remembering past situations similar to the current situation and by these situations to help resolve the current situation. The case based reasoning (CBR) is a form of reasoning by analogy $[10,20]$. The analogy searches for cause and effect relation in past situations and transfer them to the current situation. The case based reasoning research only looks for similarities or proximity relations between past situations and the current situation. The C.B.R. Considers reasoning as a process of remembering a small set of practical situations: the cases, it bases its decisions on the comparison of the new situation (target cases) with the old (reference cases). The general principle of CBR is to treat a new problem (target case) by remembering similar past experiences (base case) [10, 20]. This type of reasoning rests on the assumption that if a past experience and new circumstances are sufficiently similar, then everything can be explained or applied to past experience (base case) and remains valid when applied to the new situation which represents the new problem to solve. From a very global view, the CBR uses a basis of experience or case, a mechanism for searching and retrieving similar cases and an adaptation mechanism and evaluation solutions of selected cases emanating in order to solve the specified problem [28] (See Figure. 3).

A "case" is a structured representation of a composed history crossed or imagined [15]. According to [24], a case can be defined as a group of contextual knowledge teaching a lesson. A CBR process passes by the four following stages:

- Recall stage: further to the development of a target case, a research is performed in the database of cases to find those likely to resolve the problem.

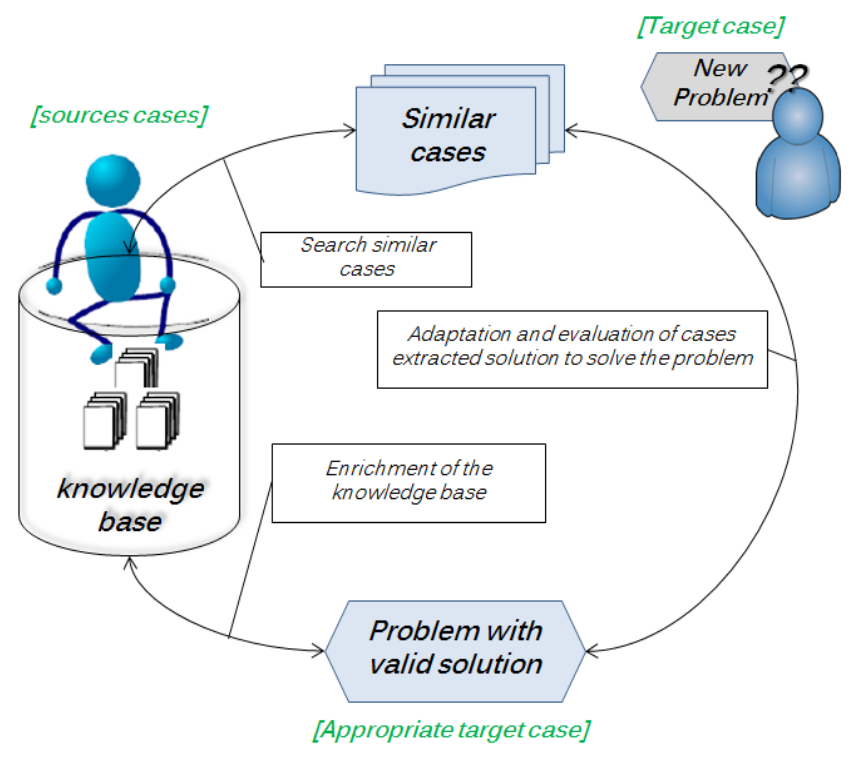

Figure 3. Cycle case based reasoning (CBR) [18].
- Adaptation stage: This stage is necessary because the recollected case is never strictly the same as the new case. It consists in changing the solution of the recollected case to consider difference between specifications of problems. It asks for specific knowledge of adaptation that is always easy neither to model nor to implement.

- Revision stage: After its generation by the system, offered solution is tested in order to be validated during the revision stage, which is generally external to the system.

- Memorization or training stage: This stage of the CBR cycle tries to improve knowledge at the origin of chess met by solution and to enrich the database of case with new resolute cases.

Three CBR representation of case exist in the art state.

\section{A. The structural model}

In this model, all important characteristics that describe a case are beforehand determined by the system designer. The similarity between two cases is measured according to the distance between the values of the same attributes. This distance is often estimated by Euclidean measures or by Hamming measures. The total similarity between two cases is habitually estimated by a sum balanced of the similarity of each attributes. All works on the adaptation of case are led as part of the structural model.

\section{B. The conversational model}

In the structural model, a problem must be completely described before the research in the database of case starts. Moreover, this requirement presupposes an expertise of the application area, which is not the case with all the users of CBR systems. As its name points, the interactive model bets on correlation between the user and the system (from which the notion of "dialogue") to define problem progressively, to be solved and to choose the most appropriate solutions. In the interactive diagram, the correlation between the system and the user is made as follows:

- The user gives to the system a short textual description of the problem that will be solved and the system calculates the similarity between this description and the "problem" section of cases. The system offers then to the user a series of questions.

- The user chooses the questions that he wants to answer. For every answer given by the user, the system reassesses the similarity of each of cases. The questions that did not have received an answer are introduced in descending order of priority.

\section{The textual modal}

The practitioners of the domain have determined the borders of the structural approach and so they offered other models to spread its application in various domains. In this approach, textual cases are "not-structured" or "semistructured". They are "not-structured" if their description is completely "Free-text". They are "semi-structured" when the text is cut up in portions labeled by descriptors such as 
"problem", "solution", etc. Textual CBR differs from that structural in whom texts are simply character strings.

\section{CONCEPT OF ACCIDENT CASE}

Certification Experts use the terminology "scenario" to express an accident. This concept is richer than the concept of cases found in literature. Indeed, an accident brings all the three complementary descriptive views of the accident (See Figures 5,6):

\section{A. Textual descrption versus textual model of cases}

It is about a text, which explains the holding of accident. For example, we give the description given by the experts for the scenario $\mathrm{N}^{\circ} 34$ in the database (See figure 4).

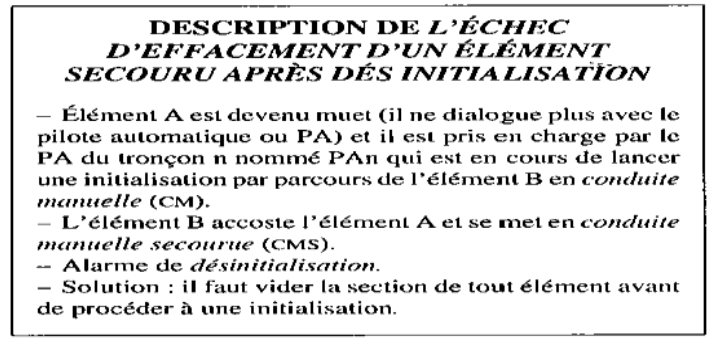

Figure 4. Textual description of an accident scenario.

This description is similar to the textual model of case in which, textual cases are "not-structured". Their description is completely in "Free-text". However, it is possible in this text to spot the problem part in sentences 1) 2) 3) and the solution part in 4).

\section{B. Static description versus strustural model of cases}

It is a group of descriptive parameters of a scenario in the form of a chip <Attribute/Values>. Then at this level, it takes a census of several characteristic parameters, which give an account of the accident description. Static description is similar to the structural model of case that was well and strongly used in the ACASYA system.

\section{Dynamic description versus conversational model of cases}

It is a dynamic view of the sequential holding of an accident in the time and in the space. This representation calls Petri in as a formalism in which places correspond to states, transitions correspond to the possibilities of evolution from a state to another. This description is related to the interactive model of case. In the structural model, the user must have in priori a good idea of all factors that can influence the resolution of his problem. However, for some problems, it is difficult to determine beforehand the aspects of situation. As its name points it out, the interactive model bets on correlation between the user and the system to define the problem progressively and to choose the most appropriate solutions. Dynamic description and its execution from a given situation (tokens put in some places) could be made only thanks to a dialogue between the system and the expert in order to bring some change in the system to reach an accident. The purpose of the expert is to generate scenarios likely to improve the exhaustiveness of the security file of the railway transportation system.

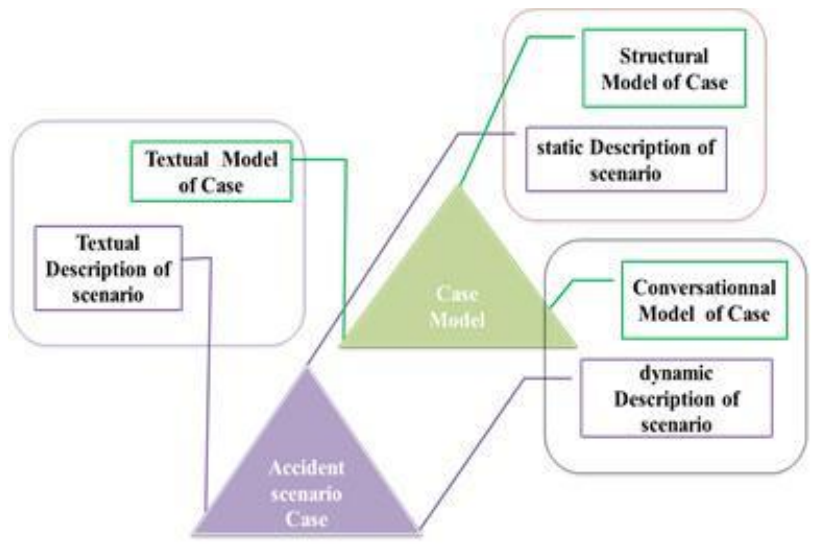

Figure 5. Case model of accident scenario.

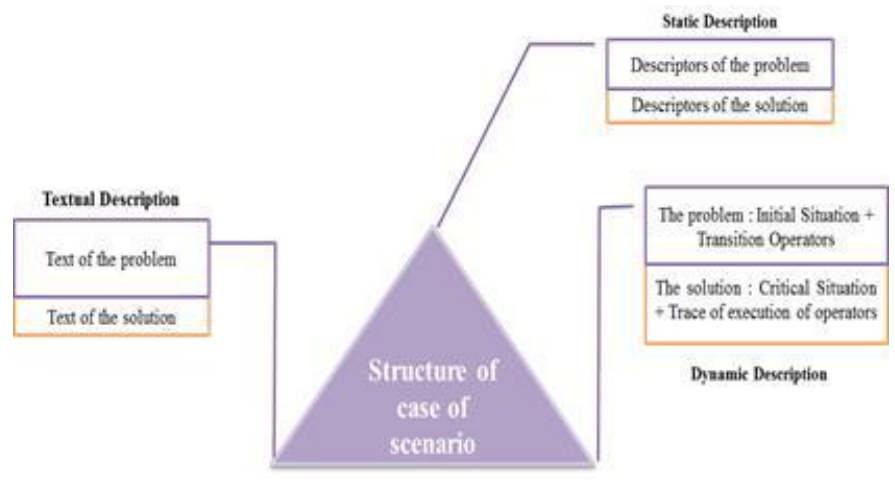

Figure 6. Structure of accident scenario case.

\section{DEVELOPING A DOMAIN ONTOLOGY}

\section{A. Presentation}

Reference [4] proposes the following definition: "an explicit specification of conceptualization" that is so far the definition most cited in the literature in artificial intelligence. This definition was modified slightly [26] as "formal specification of a shared conceptualization".

These two definitions are resumed in [27] as "a formal and explicit specification of a shared conceptualization".

- Formal: the ontology should be machine readable, which excludes natural language.

- Explicit: the explicit definition of the concepts and constraints of their use.

- Conceptualization : the abstract model of a real world phenomenon by identifying the key concepts of this phenomenon.

- Shared: the ontology is not the property of an individual, but it represents a consensus accepted by a community of users.

\section{B. The components of ontology}

It is possible and even advisable to use the plural to refer to the notion of ontology to reflect the many facets that it covers. According to [27] there are several types of anthologies according to the model domain and possibly the tasks for which they are designed. 
Ontology can be seen as a lattice of concepts and of relations between these concepts intended to represent the objects of the world under a comprehensible form at the same time by the men and by machineries. Ontology consists of concepts and relations as well as properties and axioms [2]. We drew inspiration from works of [2] to offer the model of case. A case in our system [5] represents a rail accident (See figure 7).

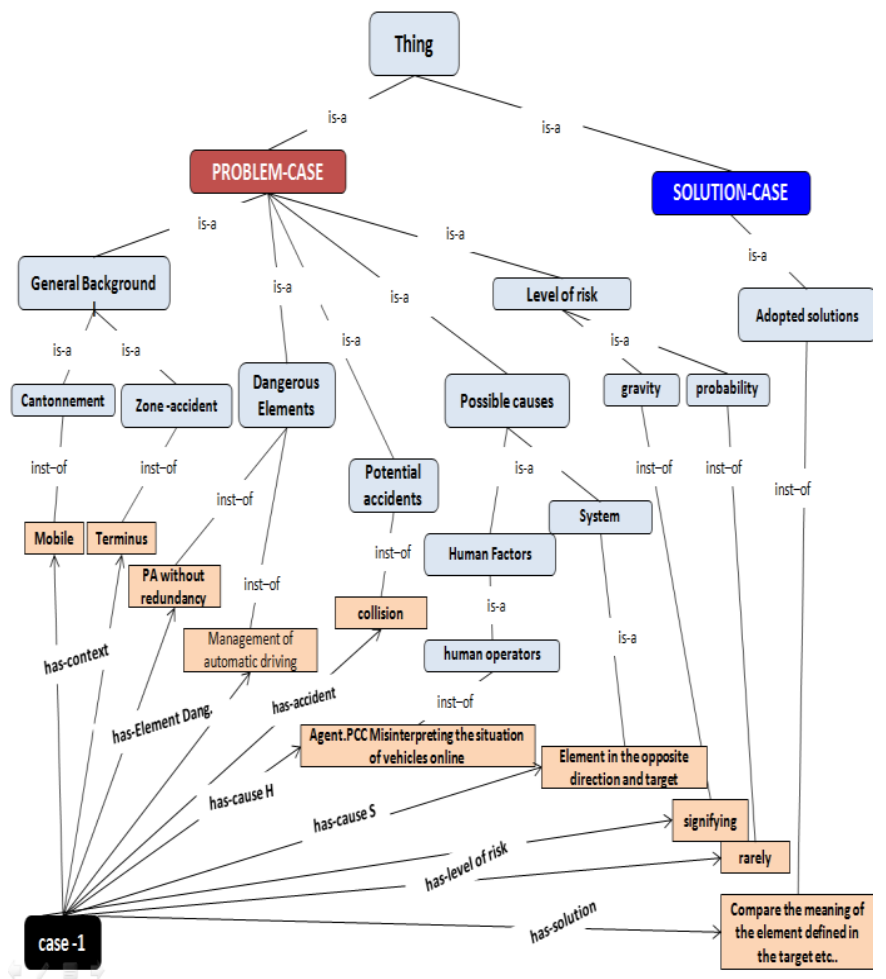

Figure 7. Case model in the domain ontology.

\section{A UNIFIED MODEL FOR REPRESENTATION AND PROBLEM SOLVING TO KNOWLEDGE REUSE}

This model allows homogenization between the knowledge representation and its exploitation. It is represented by a "scenario of resolution" of problem, which is defined as a process of problem resolution. This one is activated by an initial problem to be solved. Moreover, this model is described, since the beginning of problem up to its completion by stressing the different instants of resolution or else to the various knowledge and no mobilized views [19].

A notion of "scenario of resolution" is described according to two levels of abstractions in downward direction (See figure 8). Every level illustrates a progress in the process of resolution of the problem. "Scenario of resolution" is visible by its resolution elements, which is a part of the object view of the resolution because this element gives the trace of real resolution; on the contrary, this one would be deficient to illustrate wealth in knowledge of a scenario.

Indeed, it is the contribution of all the units of resolution, which get involved in process and give information about the totality of the scenario (from start to finish).

\section{A. The model of resolution}

This model (See Figure 8) theoretically shows the bases used in the process of problem solving. This is a view oriented "class of sub-problems" and gives methodical materials, procedures and knowledge necessitated to achieve good resolution. The view model is based on three axes:

- The first line: "class problem" informs on the family of problems concerned with the resolution. Indeed, knowledge modeled at this level is not tied to a specific problem, but to a class of similar problems. This is the Framework of problem solving.

- The second line: "Knowledge resolution" provides a formal description of knowledge that can be used in a possible resolution. This knowledge is both static (attributes, values) and dynamic (functions, methods of resolution, etc.).. Methods involved in a dynamic description can have an immediate character (offer an immediate solution), or a reducing character. A method has a reducing character when it divides a given problem into several sub-problems most basic.

- The third axis "Viewpoint" reflects a mode of observation of the problem. This mode allows characterizing the space of attributes and their rating scale. If knowledge resolution represents a formal theory for a class of problems, the viewpoint reflects sensitivity to a particular method given. This is an action plan to extract knowledge from formal resolution.

\section{B. The object of resolution}

It shows another view of the complementary model to previous resolution. Indeed, this view is just another instantiation of "model resolution" as a particular problem. This view is also three-dimensional (See Figure 8). It is based on three pillars which are the image of the three pillars of the view model:

- Pillar "Problem" which provides information about a problem or issue in particular to analyze and decompose or solve immediately;

- Pillar "Background Resolution" :Specifically, the context is represented by the set of logical and / or physical constraints imposed in problem solving. Therefore, constraints represent a "bias" in the resolution process. A constraint can be expressed by one or more logical conditions of the form <attribute value comparison>. It is important to note that the context of resolution significantly affects the view. Indeed, it is built around the operating point evidenced by the actual context of the resolution. In the specific problem of transport systems security analysis, the context of resolution is represented by "geographical zone of accident", "Human and material actors involved", "causes of accident", ...etc.

- The last pillar, called "resolution" informs on the effective resolution of the problem. This is the instantiation of knowledge by solving real parameters under particular problem. This instantiation results 
inthe production of a solution. This solution is characterized by the values and attributes set obtained after leveraging of useful methods for solving the class (i.e.: methods specified in the view).

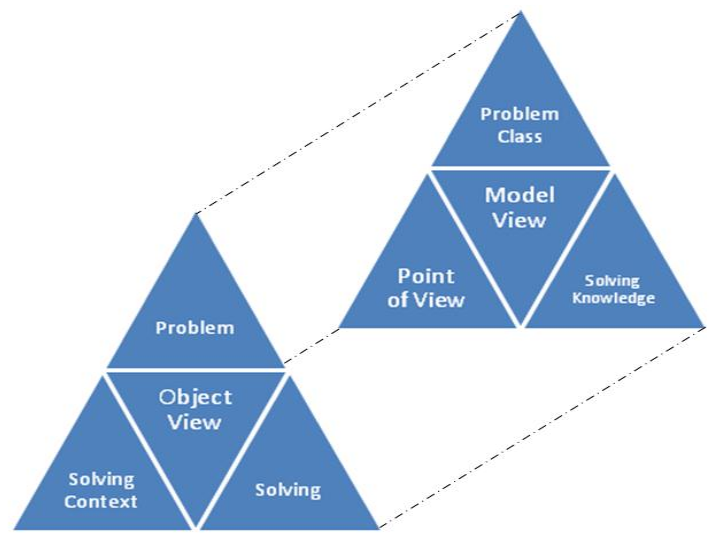

Figure 8. Complete diagram of a problem solving scenario

\section{CBR APPROACH FOR THE EVALUATION OF CASES OF ACCIDENTS}

We can note that a scenario is richer than a case as it regroups three models of case: The structural, the conversational and the textual model. In literature, it is often a matter to adopt only one of these three models. According to the multiform aspect of a scenario, it is judicious to exploit these three models and then to improve the analysis of security and not to limit itself to the static description strongly used in ACASYA to the detriment of others. We illustrate our offered approach as in figure 8 .

\section{A. Knowledge formalization}

It is an upstream stage of our approach. It is necessary to construct a platform of data for the analysis of problems. It consists in a collection of information and of domain knowledge across interviews with the experts of domain, documentary resources, and relational databases. Knowledge instituted during this stage are formalized under a database containing textual, structural and conversational cases, and a domain ontology which structures and formalizes knowledge exit from this stage.

\section{B. Classifiying the accident cases}

The classification in ACASYA showed a feedback of exploitable information. This classification segment all cases into contextual pieces sharing descriptions of problems. These contextual pieces represent a general description of a class of problem under the formalism <Attribute/value/frequency of appearance in a class $>$. In this sense, each class of accident scenarios is represented by both:

- Extensive description which regroups all scenarios belonging to the class.

- Intensive description which is materialized by a characteristic description. This one regroups all the descriptors which are more representative in the class: descriptors frequently expressed in the scenarios of this class.
This increases the deducted knowledge during the previous stage and supervises the analysis space in a simple class.

\section{Recall of accident case}

This stage is very important to focus in the more important and relevant cases instead of processing all cases included in base of cases [14], [23].

In the offered approach, we adopt a Case-Based Reasoning. This reasoning is applied in the membership class of the problem case. This one is done in order to restrain the treatment of the process in a simple class of cases. The first Stage of this reasoning is the recall of past accident cases.

It is about a research stage, which goes through all the cases of accident stocked in the class, which was spotted by ACASYA in order to identify the closest case with new constructive case in reference. A calculation of the total similarity between cases is made because of the notion of local similarity (between attributes) and by referring to the domain ontology, which is a form of normalization of all attributes in domain.

Similarity measure is calculated according to following functions:

$\operatorname{Sim}_{\text {global }}\left(\right.$ Case $_{\text {target }}$, Case $\left._{\text {source }}\right)=\sum^{\mathrm{i}=\mathrm{n}} \operatorname{Sim}_{\text {local }}\left(\mathrm{A}_{\text {target }, \mathrm{i}}, \mathrm{A}_{\text {source }, \mathrm{i}}\right) * \mathrm{~W}_{\mathrm{i}}$

With:

$\mathrm{Wi}=$ The weight of Attribute Asource, $\mathrm{i}$ and Atarget, $\mathrm{i}$

Casetarget $=$ represent the case offered by the constructor.

Casesource $=$ any case of the class identified by ACASYA.

$\mathrm{n}$ : Number of attributes of the part problem and not solution.

With:

$$
\operatorname{Sim}_{\text {local }}\left(\mathrm{A}_{\text {target }, \mathrm{i}}, \mathrm{A}_{\text {source }, \mathrm{i}}\right)=\sum^{\mathrm{k}=\mathrm{p}} \partial \mathrm{ik}
$$

$\partial \mathrm{ik}=1$ if the value of $\mathrm{Vk}$ de Atraget, $\mathrm{i}=\mathrm{Vk}$ de Asource, $\mathrm{i}$

$\partial \mathrm{ik}=0$ if the value of $\mathrm{Vk}$ de Atarget, $i=\mathrm{Vk}$ de Asource, $\mathrm{i}$

$\mathrm{P}=$ Number of descriptive values of attribute.

\section{Adaptation of accident case}

The evaluation of an accident scenario is to test the completeness and coherence. Completeness informed about the fact that the accident evaluated includes all descriptors needed for a good definition. Consistent informs on the integrity of the accident scenario evaluated and the fact that it has no unnecessary or redundant descriptors. The assessment leads to the detection of causes of the accident and the proposal of solutions to overcome this insecurity. This stage could be done according to three phases of treatment:

- Partitioning of descriptors

- Generation of adaptation rules

- Adaptation of the most similar case

1) Partitioning descriptors

The extension of the evaluation method to the set of descriptors has led to a partitioning them in 3 families (fig. 9): 
TABLE I. FAMILIES OF DESCRIPTORS IN ACCIDENT SCENARIO.

\begin{tabular}{|c|c|c|c|}
\hline $\begin{array}{l}\text { Families of } \\
\text { descriptors }\end{array}$ & $\begin{array}{c}\text { List of } \\
\text { Attributes }\end{array}$ & List of Possible Values & $\begin{array}{l}\text { Selecte } \\
\quad \text { d } \\
\text { Values }\end{array}$ \\
\hline \multirow{11}{*}{$\begin{array}{c}\text { Symptoms } \\
\text { Descriptors of } \\
\text { accident Scenario }\end{array}$} & \multirow{2}{*}{$\begin{array}{c}\text { Principle of } \\
\text { Mobile }\end{array}$} & Fixed Canton & $\mathrm{x}$ \\
\hline & & Mobile Canton & \\
\hline & \multirow[t]{3}{*}{ Risk } & Collision & $\mathrm{x}$ \\
\hline & & Derailment & \\
\hline & & Others & \\
\hline & \multirow[t]{3}{*}{$\begin{array}{l}\text { Functions of } \\
\text { Security }\end{array}$} & $\begin{array}{c}\text { Automatic Driven } \\
\text { Management }\end{array}$ & $\mathrm{x}$ \\
\hline & & Docking of trains & \\
\hline & & Others & \\
\hline & \multirow{3}{*}{$\begin{array}{l}\text { Geographical } \\
\text { Zone of } \\
\text { Accident }\end{array}$} & Terminated station & \\
\hline & & Line & $\mathrm{x}$ \\
\hline & & Others & \\
\hline \multirow{9}{*}{$\begin{array}{c}\text { Causes } \\
\text { Descriptors of } \\
\text { Accident Scenario }\end{array}$} & \multirow{3}{*}{$\begin{array}{c}\text { Involved } \\
\text { Actors }\end{array}$} & Number of trains & \\
\hline & & Operator at PCC & \\
\hline & & Others & \\
\hline & \multirow{3}{*}{$\begin{array}{l}\text { Secondary } \\
\text { Functions of } \\
\text { security }\end{array}$} & $\begin{array}{l}\text { Management of } \\
\text { Itineraries }\end{array}$ & \\
\hline & & Instructions & $\mathrm{x}$ \\
\hline & & Others & \\
\hline & \multirow[t]{3}{*}{$\begin{array}{l}\text { Summarized } \\
\text { Failures }\end{array}$} & $\begin{array}{c}\text { PR6 : Impossible Start- } \\
\text { up of train }\end{array}$ & $\mathrm{x}$ \\
\hline & & $\begin{array}{l}\text { PR2: Train with } \\
\text { collision Transmitter } \\
\text { Failure }\end{array}$ & $\mathrm{x}$ \\
\hline & & $\begin{array}{l}\text { PR17: Alarm masking } \\
\text { by docking }\end{array}$ & $\mathrm{x}$ \\
\hline \multirow{2}{*}{$\begin{array}{l}\text { Cure Descriptors } \\
\text { of Accident } \\
\text { Scenario }\end{array}$} & \multirow[t]{2}{*}{$\begin{array}{l}\text { Adopted } \\
\text { Solutions }\end{array}$} & $\begin{array}{l}\text { SA12: Check effective } \\
\text { docking of Train }\end{array}$ & $\mathrm{x}$ \\
\hline & & Others & \\
\hline
\end{tabular}

- Descriptors like "symptoms" are used to characterize the problem and the context in which the story unfolds insecurity. They concern such descriptors:

$($ Risk $=$ Collision $)($ Principle Mobile $=$ township fixed $)$ (Location $=$ Terminus) $($ Actors involved $=$ mobile operator $) \ldots$ etc...

- The type descriptors "cause" that define human failures and / or material leading to danger. Failures elementary incorporated more generic groups designated "Summarized Failures" (PR) such as:

(Summarized Troubleshooting $=$ invisible element of the driving area Full Auto).

- The type descriptors "cure" solutions that are intended to maintain or restore the operating system and therefore limit the impact of failures. In the context of transport, these remedies are called Adopted Solutions (SA). The remedies are usually offered by the manufacturer of the transport system in terms of palliative risk such as:

"Solutions Adopted" = "check list L4 is free."

\section{2) Generation of adaptation rules}

The generation of adaptation rules is made by comparing the cases of accident belonging to the same class. To do this, a learning algorithm of rules was applied. We chose the algorithm CHARADE [13] to induce a set of rules for adaptation from the class of accident scenarios identified in the previous step by the classifier. Interest CHARADE system is it does not produce a rule base isolated that is to say the rules of classification of type:

\section{IF conjunction of descriptors THEN Class.}

But it can produce outright by inductive inference, a system of rules of completion type:

IF conjunction1 of descriptors THEN Conjunction2 of descriptors.

The empirical induction system CHARADE can detect similarities between scenarios insecurity of the same class, considered as training examples, thus forming adaptation rules. The rules induced then contribute to the CBR process. The evaluation provides an overall assessment of the completeness and consistency of the scenario studied.

The analysis of the natural process of reasoning experts reveals that in fact, experts are alarmed by the symptoms that they are looking for causes and then determine remedies. Two stages may be distinguished in the expert reasoning:

- First step: symptoms suggest causes;

- Second stage: symptoms and causes require remedies;

However, some symptoms may bring in experts to consider other causes and some allow evoking others. This leads as shown in Figure 10, to enrich the previous line of reasoning.

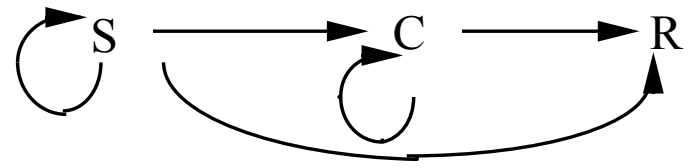

Figure 9. Natural reasoning of experts.

This analysis motivates the construction of two systems of rules:

- One Recognition Causes System (SRC) which contains rules of the form:

IF so (s) symptom (s)

THEN it (s) generally coexist (s) with such (s) other (s) symptom (s)

AND is (are) emanated from such (s) cause (s).

Example:

IF SYMPTOMS: $($ Risk = Collision $)$ 
AND (Security Functions = Alarm Management)

AND (Involved Actors = Itinerant Operator)

THEN SYMPTOMS: (Security Functions = Docking)

AND CAUSES: (Summarized Failures = PR17).

- One Recognition Remedies System (SRR), which includes rules of the form:

\section{IF the presence of such (s) symptom (s) \\ AND IF it (s) emanate (s) from so (s) cause (s) \\ THEN it(s) generally coexist (s) with such (s) other symptom (s)}

AND so (s) cause (s)

AND require (s) such (s) remedy (ies).

Example:

IF SYMPTOMS: $($ Risk = Collision $)$

AND (Security Functions = Alarm Management)

AND (Involved Actors = Itinerant Operator)

AND CAUSES: $($ Summarized Failures = PR17)

THEN SYMPTOMS: (Security Functions = Initialization)

AND CAUSES: $($ Summarized Failures = PR2)

AND REMEDIES: (Adopted Solutions = SA12).

The use of CHARADE system [13] has generated two induction systems with 80 rules about rules for SRC and 50 rules for the SRR. This large number of rules can be explained by the existence of rules of completion that is to say the rules go descriptors symptoms and conclude on other symptoms to complete the description.

\section{3) Adaptation of Case}

To illustrate the method of adaptation of case, let us call the Case To Evaluate as (CTE) and the Most Similar Case obtained by CBR mechanism of recall as (MSC).

According to this we obtain two cases:

- $\quad$ The case to evaluate named CTE is composed of three components: Symptoms $\left(\mathrm{S}_{\mathrm{CTE}}\right)$; Causes $\left(\mathrm{C}_{\mathrm{CTE}}\right)$; Remedies $\left(\mathrm{R}_{\mathrm{CTE}}\right)$.

\section{$\mathrm{CTE}=\mathrm{S}_{\mathrm{CTE}} \cup \mathrm{C}_{\mathrm{CTE}} \cup \mathrm{R}_{\mathrm{CTE}}$ (Case To Evaluate)}

- The Most similar case named MSC is composed of three components: Symptoms $\left(\mathrm{S}_{\mathrm{MSC}}\right)$; Causes $\left(\mathrm{C}_{\mathrm{MSC}}\right)$; Remedies $\left(\mathrm{R}_{\mathrm{MSC}}\right)$

\section{$\mathrm{MSC}=\mathrm{S}_{\mathrm{MSC}} \cup \mathrm{C}_{\mathrm{MSC}} \cup \mathrm{R}_{\mathrm{MSC}}$ (Most Similar Case)}

The first step is to determine relevant descriptors which are defined as descriptors envisaged both in case to evaluate and in the most similar case selected. Relevant descriptors are common descriptors listed in the case to evaluate and the historical case remembered by the CBR system. In this way, we obtain three kinds of relevant descriptors as follows:
- $\quad$ Relevant Symptoms labeled $\left(\mathrm{S}_{\mathrm{Rel}}\right)$

$\left(\mathrm{S}_{\mathrm{Rel}}\right)=\mathrm{S}_{\mathrm{CTE}} \cap \mathrm{S}_{\mathrm{MSC}}$

- $\quad$ Relevant Causes labeled $\left(\mathrm{C}_{\mathrm{Rel}}\right)$

$\left(\mathrm{C}_{\mathrm{Rel}}\right)=\mathrm{C}_{\mathrm{CTE}} \cap \mathrm{C}_{\mathrm{MSC}}$

- Relevant Remedies labeled $\left(\mathrm{R}_{\mathrm{Rel}}\right)$

$\left(\mathrm{R}_{\mathrm{Rel}}\right)=\mathrm{R}_{\mathrm{CTE}} \cap \mathrm{R}_{\mathrm{MSC}}$

Three techniques are here used to adapt the most similar case selected by CBR process.

a) Deductive Adaptation

This technique uses deductive inference to obtain an adapted case in two inferences according to adaptation rules systems labeled SRC and SRR and driven by Relevant Symptoms $\left(\mathrm{S}_{\mathrm{Rel}}\right)$ as follows:

Inference 1:
$\left(\mathrm{S}_{\mathrm{Rel}}\right)$ ? ? Deduction By SRC ? $\mathrm{S}_{\mathrm{Comp} 1}, \mathrm{C}_{\mathrm{Comp} 1}$

Inference 2 uses descriptors obtained by inference 1:

$\left\{\mathrm{S} \mathrm{Rel}_{\mathrm{R}} \cup \mathrm{S} \mathrm{Comp1} \cup \mathrm{C}_{\mathrm{Comp} 1}\right\}$ ? ? Deduction By SRR ? $\mathrm{S}$ Comp2, $\mathrm{C}_{\text {Comp2 }}, \mathrm{R}_{\text {Comp1 }}$

Case obtained after adaptation is:

$\left\{\left(\mathrm{S}_{\mathrm{Rel}} \cup \mathrm{S} \mathrm{Comp} 1 \cup \mathrm{S}_{\mathrm{Comp} 2}\right) ;\left(\mathrm{C}_{\mathrm{Comp} 1} \cup \mathrm{C}_{\mathrm{Comp} 2}\right) ;\left(\mathrm{R}_{\mathrm{Comp} 1}\right)\right\}$

The first packet of Compatible descriptors obtained by inference is labeled Comp1; the second one is labeled Comp2.

\section{b) Abdicative Adaptation}

This technique uses abdicative inference to obtain an adapted case in two inferences according to adaptation rules systems labeled SRR and SRC and driven by Relevant Remedies $\left(\mathrm{R}_{\mathrm{Rel}}\right)$ as follows:

Inference 1:

$\left(\mathrm{R}_{\mathrm{Rel}}\right)$ ? ? Abdication By $S R R$ ? $\mathrm{S}_{\mathrm{Comp} 1}, \mathrm{C}_{\mathrm{Comp} 1}$

Inference 2 uses descriptors obtained by inference 1:

$\left\{\mathrm{S}_{\mathrm{Comp} 1} \cup \mathrm{C}_{\mathrm{Comp} 1}\right\}$ ? ? Abdication By SRC ? $\mathrm{S}_{\mathrm{Comp} 2}$

Case obtained after adaptation is:

$\left\{\left(\mathrm{S}_{\mathrm{Comp} 1} \cup \mathrm{S}_{\mathrm{Comp} 2}\right) ;\left(\mathrm{C}_{\mathrm{Comp} 1}\right) ;\left(\mathrm{R}_{\mathrm{Rel}}\right)\right\}$

c) Abdicative and Deductive Adaptation

This technique uses both abdicative and deductive inference to obtain an adapted case in two inferences according to adaptation rules systems labeled SRC and SRR and driven by Relevant Causes $\left(\mathrm{C}_{\mathrm{Rel}}\right)$ as follows:

Inference 1: (Abdication)
$\left(\mathrm{C}_{\mathrm{Rel}}\right)$ ?? ? Abdication By SRC ? $\mathrm{S}_{\mathrm{Comp} 1}$
Inference 2: (Deduction)
$\left\{\mathrm{S}_{\mathrm{Comp} 1} \cup \mathrm{C}_{\mathrm{Rel}}\right\}$ ? ? Deduction By SRR ? $\mathrm{S}_{\mathrm{Comp} 2}, \mathrm{C}_{\mathrm{Comp} 2}, \mathrm{R}$
$\mathrm{Comp}$
Case obtained after adaptation is:




$$
\left\{\left(\mathrm{S}_{\mathrm{Comp1}} \cup \mathrm{S}_{\mathrm{Comp} 2}\right) ;\left(\mathrm{C}_{\mathrm{Rel}} \cup \mathrm{C}_{\mathrm{Comp1}} \cup \mathrm{C}_{\mathrm{Comp} 2}\right) ;\left(\mathrm{R}_{\mathrm{Comp1}}\right)\right\}
$$

\section{E. Revision of accident cases}

After adaptation, the solution of the new structural target case is got. This got case should be reviewed by the experts aiming the validation and though to allow toping it up at the root of case and to enrich it by indexing them and by training.

\section{F. Training}

The solution got during the previous stage and validated by the expert of domain is topped up at the root of case and then to enrich it, and consequently to enrich its indexes. In addition, this resolution trace is archived in the form of a "scenario of resolution" of problem, which could be reused completely in the future.

\section{G. Database of resolution scenario}

The main contribution of this approach is the harmonization between knowledge representation and its exploitation. Moreover, this latter by using a generic model of representation and resolution offered by [19]. The projection of this model in our context was as follows:

For the object view incorporated of three pillars (Problem, Context of resolution and resolution), we divide knowledge as follows:

- Problem: it contains the symptoms description of the accident case by considering its membership class.

- Resolution context: This contained the knowledge of the context of the problem, such as Causes descriptors.

- Solving: This pillar is by equivalence of its definition contains Remedies descriptors such as the adopted solution deducted from CBR.

For the model view incorporated of three pillars (Class of problem, Point of view and knowledge of resolution), we divide knowledge as follows:

- Class of problem: it is the description of the membership class of the problem generated by ACASYA. This class is represented by extensive description in term of accident scenarios enumerated.

- Point of view: it is the modality of the problem observation, it is represented by the point of view of resolution (Structural/ or conversational/ or textual). In our first study we focus on structural CBR.

- Knowledge of resolution: it is capitalized by grouping the adaptation rules of the class (SRC and SRR), characteristic descriptions of the classes of problems, the domain ontology and the index of the accident cases used during the CBR process, etc.

\section{H. Implementation of the offred approach}

We attract in this section to introduce the model system that assess the offered approach. This model although it is still under the development stage, we can describe its general architecture and introduce some windows of the application (See Figure 11).

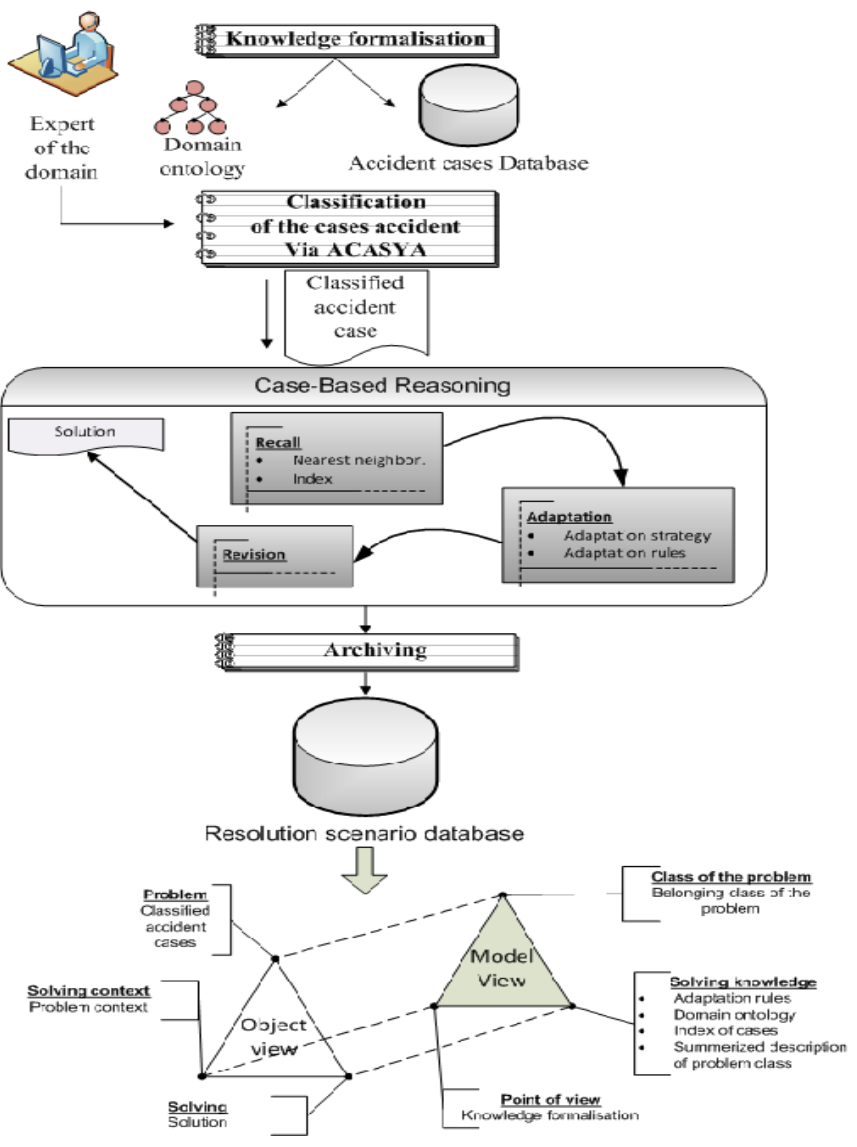

Figure 10. Complete diagram of the proposed approach.

The architecture of the ongoing model spreads out mainly on five modules:

- A preconception module, which includes the part of knowledge formalization having the goal to structure the knowledge by defining the domain ontology under an XML format, keyboarding of the domain dictionary. Expert knowledge is defined throughout by the specification of similarity parameters.

- A module of accident cases management, which allows addition, modification and removal of accident cases according to their representation models: textual, structural and conversational.

- A classification module of accident cases,same as ACASYA.

- A module represented by an engine of CBR reflecting its different stages (Recall, adaptation, revision and training).

- A module for knowledge archiving in a database of "scenario of resolution", which keeps the trace of the problem resolution as well as the used knowledge for the resolution. This scenario could be reused in the subsequent sessions of exploitation of the help system.

Finally, we introduce into this paper an example of an execution window of the system, which is under developing: 


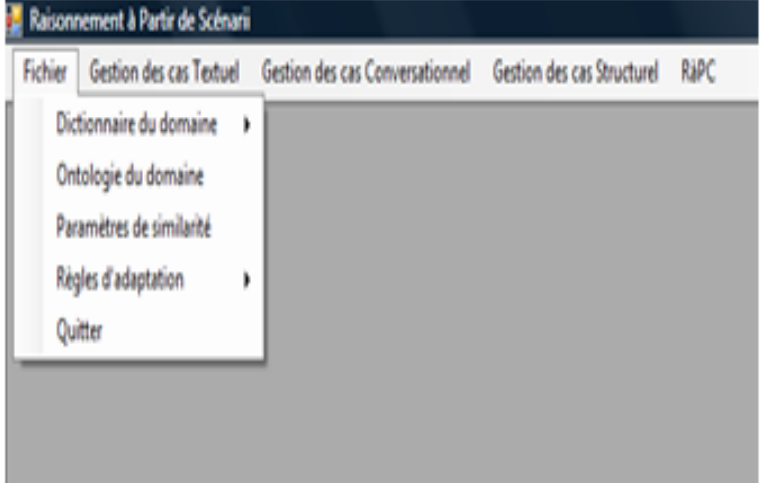

Figure 11. The main window of the system.

This window, which represents the main window of application, allows going through all the functionality described in the architecture of the system.

\section{CONCLUSION}

We introduced in this article the first works made concrete by our approach and notably the general architecture of the CBR system. This architecture articulates around two processes: an off-line process and other one on-line, which use different types of knowledge for the problem solving. In result, the introduced work as a part of this article follows from the problems of knowledge management of a critical domain: the security and especially, the railway accident. Although the application field constitutes in itself originality, we can stress the still generic character and the opening of knowledge model.

This article presents just a work in progress. We must emphasis our study on others methods of CBR such as textual and conversational CBR. Currently, we work on the acquisition of knowledge relating to reasoning and to the improvement of the model worked out of knowledge, especially ontology, to enrich it by concepts relating to the dynamic description of the accident scenario. It is judicious to study the recent works in the field of CBR which used ontology in different ways: to describe and to structure cases [15], to offer independent models of domain [9], CCBRONTO [6]; to calculate semantic similarity [27], to treat the heterogeneity of cases [2], etc.

\section{REFERENCES}

The template will number citations consecutively within brackets [1]. The sentence punctuation follows the bracket [2]. Refer simply to the reference number, as in [3] - do not use "Ref. [3]" or "reference [3]" except at the beginning of a sentence: "Reference [3] was the first ..."

Number footnotes separately in superscripts. Place the actual footnote at the bottom of the column in which it was cited. Do not put footnotes in the reference list. Use letters for table footnotes.

Unless there are six authors or more give all authors' names; do not use "et al.". Papers that have not been published, even if they have been submitted for publication, should be cited as "unpublished" [4]. Papers that have been accepted for publication should be cited as "in press" [5]. Capitalize only the first word in a paper title, except for proper nouns and element symbols
For papers published in translation journals, please give the English citation first, followed by the original foreign-language citation [6].

[1] A. Aamodt, "A Knowledge-Intensive, Integrated Approach to Problem Solving and Sustained Learning,". PhD Thesis, University of Trondheim, Norway (1991).

[2] A. Abou Assali, "Acquisition des connaissances d"eadaptation et Traitement de l'hétérogénéité dans un système de ràpc basé sur une Ontologie. Application au diagnostic de la défaillance de détecteurs de gaz,". Thèse De Doctorat (2010).

[3] A. Abou Assali, D. Lenne, and B. Debray, "Ontology Development for Industrial Risk Analysis,”. In IEEE International Conference On Information, Communication Technologies : From Theory ToApplications (ICTTA'08), Damascus, Syria, April 2008c.K. Elissa, "Title of paper if known," unpublished.

[4] A. Maalel, andH.Hadj-Mabrouk,"Contributionof CaseBasedReasoning(CBR) in the Exploitation of Return of Experience. Application to Accident Scenarii in Rail Transport,". SIIE'2010, 3rd International Conference OnInformationSystems AndEconomic Intelligence,18-20february2010,Sousse,Tunisia.

[5] ] A. Maalel, H. Hadj Mabrouk,L. Mejri and H. Ben Ghezela, "Development of an Ontology to Assist the Modeling of an Accident Scenario: Application on Railroad Transport,". Journal Of Computing, Volume 3, Issue 7, July 2011.

[6] B. Dìaz-Agudo,and P.A. Gonzàlez-Caler, "CBROnto : a task/method ontology for CBR,". Procs. Of The 15th International FLAIRS, 2 :101106. 2002.

[7] ]C. Roche," Le terme et le conceptfondements d'une ontoterminologie,". PremièreConférence Terminologie \& Ontologie : Théories et Applications. TOTh 2007.

[8] C. Roche, "Ontology: a Survey,". The 8th Symposium On Automated Systems, IFAC. Goteborg, Sweden, September 22-24, 2003.

[9] G. Gauchía, B. Díaz-Agudo, and P.A. González-Calero, "OntologyDriven Development of Conversational CBR Systems,”. In Advances In Case-Based Reasoning, Proceedings Of The 8th European Conference (ECCBR'06), volume 4106, pages 309-324, Turkey. Springer Berlin / Heidelberg. ISBN 978-3-540-36843-4, (2006).

[10] H. Hadj-Mabrouk, "Acquisition et évaluation des connaissances de sécurité des systèmes industriels. Application au domaine de la certification des systèmes de transport guidés,". Thèse d"'Habilitation à Diriger des Recherches, Université De Technologie De Compiègne 1998

[11] J. Charlet,." Constructionderessources terminologiquesou ontologiquesà partirde textes,", Cadre Unificateur, (2004).

[12] J.A. Recio-Garcìa, B. Dìaz-Agudo, P. González-Calero, and A. Sanchez, "Ontology based CBR with COLIBRI,". Applications And Innovations In Intelligent Systems, $14: 149-162,2006$.

[13] J.G. Ganascia,"L'apprentissage symbolique,", Encyclopédie De La Communication - PUF, S/direction de Lucien SFEZ, 1991

[14] J. Kendall_Morwick, D. Leake, "Facilitating representation and retrieval of structured cases : Principles and toolkit", Information Systems (2012) in press.

[15] J.Kolodner, "Case-Based Reasoning,".Morgan-Kaufmann Publishers, Inc., 668 pages, 1993.

[16] J. Lieber, M. d'aquin, S. Brachais, and A. Napoli, "Une étude comparative de quelques travaux sur l'acquisition de connaissances d'adaptation pour le raisonnement à partir de cas". In Actes du 12ème atelier de raisonnement à partir de cas (RàPC'04), 2004.

[17] L. Mejri,"Une démarche basée sur l"eapprentissage automatique pour l"aide à l"évaluation et à la génération de scenarios d"accidents. Application à l"analyse de sécurité des systèmes de transport automatisés,". Université de valenciennes, 6 décembre 1995.

[18] L. Mejri., A. Maalel. and H. Ben Ghezala, "Simulation de cas d'accidents pour l'aide à la décision.Application à la sécurité des systèmes de transport ferroviaires automatisés,". Atelier Aide EGC 2012, $12^{\text {ème }}$ Conférence Francophone Sur l'Extraction Et La Gestion Des Connaissances, 31 janvier au 3 février 2012, Bordeaux. 
[19] L. Mejri, H. Hadj mabrouk, and P. Caulier,"Un modèle générique unifié de représentation et de résolution de problème pour la réutilisation de connaissances. Application à l'analyse de sécurité des systèmes de transport automatisés,". Revue Recherche, Transport Sécurité, RTS $\mathrm{N}^{\circ} 103,2009$.

[20] L. Mejri, and P. Caulier, "Formalisation of a scenario concept to dynamic problem solving,", 24th European Annual Conference on Human Decision Making and Manual Control EAM, Athens, 17-19 October 2005.

[21] M. H. Mazouni, "Pour une Meilleure Approche du Managementdes Risques : De la Modélisation Ontologique duProcessus Accidentel au Système Interactif d'Aide à laDécision" ,Thèse de doctorat 2008.

[22] M. Lopez, A. Gomez-Perez, and M. Rojas-Amaya, "Ontology's crossed life cycle". The 12th International Conference On Knowledge Engineering And Knowledge Management, EKAW-2000.

[23] M. Minor, S. Montani, "Preface", In Proceedings Of The ICCBR, Workshop on Process Oriented Case Based Reasoning, 2012.

[24] M. Ushold,and M. Gruninger, "Ontologies: principles, methods, and applications". Knowledge Engineering Review, 11(2):93-155, 1996.

[25] N. Friedman, and D. McGuiness, "OntologyDevelopment", 101: A Guide to Creating Your FirstOntology. 2001.

[26] T. Gruber, "A translation approach to portable ontology specifications.Knowledge”.AcquisitionJournal. 5:199 -220, 1993.

[27] W.N. Borst, "ConstructionofEngineering Ontologies".Thèsede doctorat, Center forTelematicaandInformationTechnology,Université deTweenty, Enschede, 1997.

[28] W.S. Han, M.D. Pham, J. Lee, R. Kasperovics, and J.X. Yu, "igraph in action : performance analysis of disk based graph indexing techniques,
In Proceedings Of The International Conference On Management Of Data, SIGMOD’11, New York, NY, USA, ACM (2011) 1241-1242.

\section{AUTHORS PROFILE}

MejriLassaâd

Researcher in Laboratory of Automatic,Industrial/HumanComputer

Sciences.LAMIH CNRS UMR 8530.Valenciennes - France.

Dr In Computer Sciences - Faculty of Sciences In Bizerta-Computer Science

Department.

University of Carthage

7021 JARZOUNA -BIZERTE - TUNISIE

Tél. : 216-98-362222 - Fax : 216-72-590566.-

E_mail : mejrilassad@yahoo.fr

\section{MadiSofian}

Researcher in RIADI Laboratory of ENSI (National School of Computer

Sciences), Tunis - Tunisia.

Manouba University - Tunis - Tunisia

P.O. Box 88 Hached Gabes 6001 Tunisia

Tél. : 216-22-793737 - E_mail : sofian.madi@gmail.com

\section{Ben GhezalaHenda}

Directorof RIADI Laboratory - ENSI (National School of Computer

Sciences). Tunis - Tunisia.

Professor in Computer Sciences -ENSI (National Shool of Computer

Sciences), Computer Science Department - Tunis-.Tunisia

Manaouba University- TUNISIA.

E_mail :hhbg.hhbg@gnet.tn 